\title{
ENSINO E MEDIAÇÃO DIALÉTICA
}

ARNONI, Maria Eliza B. ${ }^{1}$

Este texto apresenta as investigações do "Grupo de Pesquisa - Ensino e Mediação Dialética" $(\mathrm{CNPq})$ e expressa as necessidades acadêmicas que confluíram para sua organização, os enfrentamentos teóricos que se delineiam em uma aula quando se considera relevante no ensino, além dos conteúdos, a opção metodológica do professor. A formação do aluno é influenciada pelo processo de ensino, incluindo, neste, a opção metodológica do professor, a qual se expressa, em especial, nas posturas assumidas pelo estudante, em sua vida cotidiana. Em relação à pesquisa acadêmica da área educacional, baseadas nos pressupostos teóricos sobre a ontologia do ser social, as discussões do G.P.E.M.D. direcionam-se para a investigação do ensino, na perspectiva filosófica de práxis. em especial, os da proposição teórico-metodológica que gera a práxis educacional crítica, a aula na perspectiva da."Metodologia da Mediação Dialética"

Palavras chaves: ensino, metodologia da mediação dialética, aula como práxis.

\section{INTRODUÇÃO}

A pesquisa acadêmica produz o conhecimento científico, metódico e sistematizado em conceitos que fundamentam a linguagem específica da Ciência. Essa produção científica, relevante para o desenvolvimento do país, constitui um conhecimento histórico-social que expressa as relações político-econômicas vigentes no período em que foi produzido, sendo, ao mesmo tempo, condicionante da sociedade e por ela condicionado. E, neste texto apresento os pressupostos teóricos da Mediação (dialética) e a proposição metodológica sobre a organização metodológica do conceito de ensino, por intermédio da "Metodologia da Mediação dialética" (doravante denominada de "M.M.D.").

\section{PRESSUPOSTOS TEÓRICOS}

\subsection{Práxis}

Para Lefebvre (1979), a práxis é um ato, é a relação dialética entre a natureza e o homem, as coisas e a consciência. Ela existe em três níveis: o repetitivo, o mimético e o inovador. Para o autor, o repetitivo e o inovador encontram-se situados em dois pólos e, entre os dois, encontra-se o mimético. A práxis repetitiva recomeça os mesmos gestos, os mesmos atos em ciclos determinados. A práxis mimética segue modelos; pode suceder que, imitando, ela chegue a criar, mas sem saber como nem por quê; mais freqüentemente ela imita sem criar. Quanto à práxis inventiva e criadora, ela atinge seu nível mais elevado na atividade revolucionária. Esta atividade pode ser exercida tão bem no campo do conhecimento e da cultura (a ideologia), como no da ação política.

O autor caracteriza a práxis inventiva como expressão do mais alto grau criador, a qual inclui a teoria que ela vivifica e verifica. Para ele, essa práxis criadora compreende a decisão teórica como a decisão de ação. Ela não existe sem projeto, visto que não existe ato sem programa, práxis política sem exploração do possível e do futuro: sempre comporta uma

\footnotetext{
${ }^{1}$ Departarmento de Educação, UNESP-IBILCE de São José do Rio Preto, meliza@ibilce.unesp.br
} 
abertura sobre o possível. E, toda práxis se situa duplamente na História: em relação ao passado e em relação ao futuro, sobre o qual ela se abre buscando cria-lo. Assim, na práxis ocorrem reencontros: o pensamento reencontra a unidade com o ser, a consciência reencontra a natureza sensível ou "material" e o espírito reencontra a espontaneidade. Os resultados da práxis alienam os homens na medida em que imobilizam seu poder criador e impedem a superação de níveis inferiores da práxis.

Kosik (1995) também reporta-se à práxis, apresentando-a em diferentes níveis: num nível inferior - a comum - e num nível mais elevado - a crítica -. Na práxis comum, a atividade imediata do homem, em face à realidade: é de um ser que age objetiva e praticamente, de um indivíduo histórico que exerce a sua atividade prática no trato com a natureza e com os outros homens, tendo em vista a consecução dos próprios fins e interesses, dentro de um determinado conjunto de relações sociais.

Essa realidade apresenta-se como o campo em que o homem comum exercita a sua atividade prático-sensível, fundamento da sua imediata interação prática com a realidade. Nesse trato prático-utilitário com as coisas, o indivíduo "em situação" cria suas próprias representações das coisas e elabora todo um sistema correlativo de noções que capta e fixa o aspecto fenomênico da realidade. As formas fenomênicas da realidade que se reproduzem imediatamente na mente daqueles que realizam uma determinada práxis histórica, como conjunto de representação do pensamento comum, são diferentes e muitas vezes absolutamente contraditórias à lei do fenômeno, com a estrutura da coisa e, portanto, com a sua essência e o seu conceito correspondente. Essa práxis utilitária gera o senso comum correspondente e, para Kosik, a práxis utilitária imediata e o senso comum a ela correspondente colocam o homem em condições de orientar-se no mundo, de familiarizar-se com as coisas e manejá-las, mas não proporcionam a compreensão das coisas e da realidade.

Essa práxis comum decorre do complexo de fenômenos que povoam o ambiente cotidiano que, com sua regularidade, imediatismo e evidência penetram na consciência dos indivíduos agentes, assumindo um aspecto independente e natural que constitui o mundo da pseudoconcreticidade. Para Kosik (1995), fenômeno é aquilo que se manifesta imediatamente, primeiro e com maior freqüência ocultando a essência do fato. Por isso, o agir comum gera como produto dessa pseudoconcreticidade o pensamento comum, ou melhor, um nível inferior de práxis, a comum ou a fetichizada. Esse aspecto fenomênico da coisa é produto natural da práxis cotidiana. Depreende-se, então, que a práxis utilitária cotidiana cria o pensamento comum como forma de seu movimento e de sua existência. Portanto, o pensamento comum é a forma ideológica do agir humano de todos os dias e a representação da coisa é a projeção, na consciência do sujeito, de determinadas condições históricas. Assim, para que ocorra a superação dessa práxis torna-se necessário destruir a aparente independência do mundo dos contatos imediatos de cada dia. Na superação da práxis comum, o pensamento dialético tem que destruir essa pretensa independência dos fenômenos (pseudoconcreticidade), demonstrando o seu caráter mediato e apresentando, contra a sua pretensa independência, a prova de seu caráter derivado. 
A possibilidade dessa superação decorre quando o sujeito toma consciência de que produz a realidade e que, portanto, pode mudar de modo revolucionário essa realidade humano-social, porque ele é o produtor dela. Essa realidade humano-social constitui-se na unidade da produção e produto do sujeito e objeto. Portanto, o mundo real é um mundo em que as coisas, as relações e os significados são considerados como produto do homem social, e onde o próprio homem se revela como sujeito real do mundo social, um mundo em que a verdade não é dada e predestinada, não está pronta e acabada, impressa de forma imutável na consciência humana, enfim, é o mundo em que a verdade devém (Kosik, p.23-24).

O autor apresenta como qualidades da práxis humana as duas formas ou os dois graus de conhecimento da coisa (objeto), a representação e o conceito. Portanto, na superação do conhecimento sensível e intuitivo (representação) pelo racional e teórico (conceito) ocorre, também, a superação da práxis comum pela crítica ou do pensamento comum pelo pensamento racional. Compreende-se que o caminho para buscar um nível mais elevado, pela superação do nível inferior, é o mesmo para o conhecimento, o pensamento e a práxis. Cada grau do conhecimento humano sensível ou racional, cada modo de apropriação da realidade, é uma atividade baseada na praxis objetiva da humanidade, portanto, ligada a todos os outros vários modos, em medida maior ou menor (Kosik, p.30).

A práxis representa a unidade entre a teoria e a prática e, na dependência de sua compreensão, pode se expressar em diferentes graus. Como fato, a práxis não se apresenta como um movimento uniformemente regular, nem se comporta de maneira linear: ela é singular, particular e possui característica própria e, por este motivo, ela não se revela integralmente e de imediato e, nesse caso, se expressa como fenômeno. Isso é melhor compreendido por intermédio das asserções de Kosik (1995): a realidade se apresenta por fenômenos dos quais percebem-se facetas, dada sua complexidade e, essa maneira fragmentária com que a realidade se apresenta oculta a essência do fato, dificultando sua compreensão direta e imediata. Nessa perspectiva, para buscar a organização da realidade é necessário compreender que o fenômeno é fragmento do fato e descobrir a sua essência. Para o autor, o fenômeno não é, portanto, outra coisa senão aquilo que - diferentemente da essência oculta - se manifesta imediatamente primeiro e com mais freqüência. Este pressuposto mostra que no fato existe algo definido como essência ou verdade oculta, que é distinta do fenômeno que se manifesta imediatamente e de forma fragmentária. Assim, a percepção imediata do fenômeno não possibilita apreender diretamente sua essência. Depreende-se, então, a existência, num mesmo fenômeno, de uma realidade aparente, por meio da qual ele se revela de imediato, e a existência da sua essência, que se apresenta imediatamente oculta.

Para Kosik (1995), o conhecimento realiza-se como separação de fenômeno e essência, de secundário e essencial, pois só por meio dessa separação pode-se mostrar o caráter específico do fenômeno, e com isso, a demonstração de sua coerência interna. Essa decomposição do todo é elemento constitutivo do conhecimento. Para o autor, esses sentidos por meio dos quais o homem descobre a realidade e o sentido dela são um produto históricosocial. Daí, depreender que o pensamento comum ou senso comum do homem comum, enquanto um produto histórico-social, necessita ser valorizado e explicitado para o próprio sujeito que pretende superá-lo e, portanto, considerá-lo como ponto de partida (pensamento 
comum) e de chegada (pensamento crítico) da superação. Segundo o autor, o ponto de partida do exame deve ser formalmente idêntico ao resultado. Este ponto de partida deve manter a identidade durante todo o curso do raciocínio visto que ele constitui a única garantia de que o pensamento não se perderá no seu caminho. Mas o sentido do exame está no fato de que no seu movimento em espiral ele chega a um resultado que não era conhecido no ponto de partida e que, portanto, dada a identidade formal do ponto de partida e do resultado, o pensamento, ao concluir o seu movimento, chega a algo diverso - pelo seu conteúdo daquilo que tinha partido.

Torna-se interessante ressaltar que esse ponto de partida e de chegada centra-se no estudo de um fato e que esse fato pertence a uma dada realidade. Para o referido autor, a realidade constitui-se na totalidade concreta, isto é, num todo estruturado em curso de desenvolvimento. A totalidade significa a realidade como um todo estruturado, dialético, no qual ou do qual um fato qualquer (classes de fatos, conjunto de fatos) pode vir a ser racionalmente compreendido. Os fatos são conhecidos da realidade se são compreendidos como fatos de um todo dialético, entendidos como partes estruturais do todo. Assim, cada fato pode ser compreendido como momento do todo e desempenha uma dupla função, a de definir a si mesmo e a de definir o todo. Assim, os fatos isolados são meras abstrações, são momentos separados do todo, os quais só quando inseridos no todo correspondente ganham significado e concreticidade. Assim também, o todo de que não foram diferenciados os fatos, enquanto momentos articulados, é um "todo abstrato" e vazio.

Depreende-se que o conceito de realidade confere qualidades ao conhecimento: entendendo a realidade como uma congérie de fatos, o conhecimento humano pode ser apenas um conhecimento abstrato, sistemático-aditivo. Porém, entendendo o real como um todo estruturado que se desenvolve e se cria, o conhecimento de fatos ou conjunto de fatos da realidade vem a ser conhecimento do lugar que eles ocupam na totalidade do próprio real; nesse caso seria o conhecimento dialético. Kosik afirma que a compreensão dialética da totalidade significa não só que as partes se encontram em relação de interna interação e conexão entre si e com o todo, mas também que o todo não pode ser petrificado na abstração situada por cima das partes, visto que o todo se cria a si mesmo na interação das partes.

Esse autor considera a realidade social como totalidade concreta quando se comprende, também, o homem como sujeito objetivo, histórico-social, que cria essa realidade social e que, para conhecê-la, realiza um processo cognoscitivo, um movimento circular aberto em que a investigação parte dos fatos e a eles retorna num estado qualitativamente distinto do anterior. É a cisão do todo que se dá pela oscilação dialética entre os fatos e o contexto, e o centro ativamente mediador desse processo é a investigação. Assim, "o homem não pode conhecer o contexto do real a não ser arrancando os fatos do contexto, isolando-os e tornando-os relativamente independentes" ( Kosik, p.57).

A relevância desse processo do conhecimento do real é gerar no sujeito a possibilidade, de ao realizá-lo, ser capaz de ascender a um nível mais elevado da práxis. Essa 
possibilidade encontra sustentação na afirmação do autor de que o homem tem sempre uma certa compreensão da realidade, anterior a qualquer enunciação explicativa.

\subsection{Práxis educacional.}

Práxis, etimologicamente, pode significar "prática", porém, como em nosso idioma a palavra prática tem sido usada, indistintamente, para indicar uma ação estritamente utilitária e pragmática, ela se tornou inadequada para o campo educacional. É pejorativo usar a palavra prática para representar aula, por reforçar os preconceitos que concebem a aula como espaço comum de "passar o conteúdo da disciplina", sem estabelecer a relação entre o conceito científico da referida disciplina e a forma de ensiná-lo.

Práxis é um conceito filosófico da atividade teórico-prática do ser humano em todas as áreas da sociedade. Entendida como categoria filosófica, a tensão dialética que se estabelece entre seus pares contraditórios - teoria\&prática - permite depreender e compreender a dinâmica do ambiente. O movimento dessa relação dialética, em relação ao grau de superação entre seus pólos contraditórios, expressa a qualidade da práxis, da comum à crítica. Nesta perspectiva, na práxis pode-se unir conscientemente pensamento e ação - o devir do ser social - e isso possibilita a ação crítica do ser social, no sentido da transformação.

Esse pressuposto teórico desmitifica a concepção usual de práxis e de prática como algo contraditório, geralmente, utilizadas para diferenciar as classes sociais dos sujeitos: os que pensam, desenvolvem a práxis e, os que executam, desenvolvem a prática. Neste aspecto, torna-se necessário enfatizar que todo agir prático do sujeito constitui uma práxis, partindo do princípio que todo ser social em situação age e pensa e, portanto, cria suas próprias representações do contexto num sistema correlativo de noções que elabora durante o seu agir, o seu pensamento. No entanto, dependendo do grau de consciência que o sujeito (ser social) tem das relações entre o pensar (teoria) e o agir (prática) em situação, a práxis pode apresentar-se em diferentes estados qualitativos, do comum ao crítico.

Nesta perspectiva, na práxis pode-se unir conscientemente pensamento e ação - o devir do ser social - e isso possibilita a ação crítica do ser social, no sentido da transformação.

A práxis é uma categoria - conceito filosófico - que permite depreender a ação do ser social e compreender sua qualidade, comum ou crítica. A práxis crítica caracteriza-se pela superação da teoria na prática ou da prática na teoria, gerando a unidade entre elas, possibilitando a transformação do real. Nela, o ser social crítico pode considerar a prática acumulada em forma de teoria, a história teórico-prático na qual insere a práxis atual e, a partir desta realidade que pretende intervir, no sentido de transformá-la, é possível a antecipação dos resultados objetivos que se pretende atingir, sob a forma de finalidades. Tendo em vista a finalidade, o sujeito elabora uma metodologia de trabalho, seleciona meios e a utilização para conseguir a transformação. Enfim, a práxis crítica é uma ação consciente, a atividade prático-teórica humana. 
Neste texto, a práxis é entendida como ação prática, conscientemente, articulada a uma fundamentação teórica. Teoria e prática são campos distintos que estabelecem entre si uma relação de tensão, sendo a mediação dialética a relação responsável pelo movimento de superação destes pólos distintos, gerando, assim, a práxis crítica, transformadora do real.

\subsection{Mediação Dialética}

Mediação é entendida como uma relação dialética (tensão) que tem por referência a diferença, a heterogeneidade, a repulsão e o desequilíbrio entre seus termos: o saber imediato e o saber mediato. Esses termos divergentes da mediação geram a contradição entre ambos, provocando a superação do imediato no mediato e possibilitando a elaboração de sínteses (aprendizagem). Assim, a mediação permite que o imediato seja superado no mediato, sem, no entanto, que o primeiro seja anulado ou suprimido pelo segundo; ao contrário, o imediato está presente no mediato.

Sob essa ótica, a Mediação pedagógico-dialética é uma relação dialética que caracteriza o processo de ensino e o processo de aprendizagem, uma vez que, em ambos, os sujeitos envolvidos lidam com saberes, o mediato e o imediato. Assim, os pressupostos teórico-filosóficos de Mediação dialética possibilita compreender as relações de tensão que se estabelecem no processo de ensino e no de aprendizagem.

A palavra mediação é normalmente utilizada para indicar uma intervenção com a qual se busca produzir um acordo, com o sentido de igualar ou homogeneizar termos. Todavia, quando entendida em uma perspectiva dialética, a mediação significa uma relação de tensão entre termos diferentes: o imediato e o mediato. Para não provocar equívocos conceituais em relação ao vocábulo mediação, optou-se pelo uso do termo Mediação Dialética. Com ele, explicita-se a origem filosófica da mediação e, mesmo incorrendo em redundância, utilizou-se o predicado "dialética" para reforçar o conceito de mediação, aqui presente. As relações pedagógicas do trabalho educativo são compreendidas como Mediação Dialética (Mediação pedagógico-dialética) e, a partir delas, torna-se possível discutir o processo de ensino e de aprendizagem.

Retomando, "Mediação Dialética" é a força de tensão gerada entre termos distintos, o imediato e o mediato, os quais se contrapõem entre si e são denominados de pares dialéticos. Esses pares dialéticos compõem as categorias filosóficas e permitem ao sujeito depreender, analisar e compreender o movimento do real, possibilitando, assim, a superação do imediato no mediato.

\section{4. “Metodologia da Mediação Dialética” (M.M.D)}

É inegável que toda teoria expressa os princípios fundantes da Ciência que lhe deu origem e que o estudo desta teoria permite depreender um caminho teórico para a investigação do real, o método: a relação teoria e método é preocupação fundamental e recorrente na pesquisa acadêmica. 
No entanto, ao compreender a característica teórica do método, delineia-se como prioridade acadêmica para a área educacional, a investigação sobre as possibilidades de se estabelecer relação consciente entre teoria e prática, para se alcançar a intencionalidade da práxis educativa. Assim, torna-se necessário investigar teoricamente o influxo do método em uma prática, como questão teórica da aplicabilidade do método, e, nesta perspectiva teórica, com vistas à prática, desenvolvo o estudo sobre metodologia de ensino, a proposição teóricometodológica que permite desenvolver a práxis educativa. Esta proposição intitula-se "Metodologia da Mediação Dialética" (M.M.D.).

O pressuposto teórico da "Metodologia da Mediação dialética" é a Mediação (categoria filosófica), força de tensão gerada entre termos distintos, o imediato e o mediato, os quais se contrapõem entre si e são denominados de pares dialéticos, que permitem ao sujeito depreender, analisar e compreender o movimento do real, possibilitando, assim, a superação do imediato no mediato.

A "Metodologia da Mediação Dialética" consiste em uma proposição metodológica formada por uma seqüência de situações de ensino (processo de ensino) que potencializa ao aluno a aprendizagem do conteúdo trabalhado (processo de aprendizagem). Essa proposição, elaborada na perspectiva da Mediação Dialética, possibilita ao professor compreender as ações de planejar, desenvolver e avaliar o processo de ensino e de intervir no processo de aprendizagem, dele decorrente, permitindo a elaboração do saber pelo sujeito da aprendizagem: o aluno. Ela exige um trabalho organizado, de forma articulada, por parte de quem ensina e de quem aprende.

Em cada situação de ensino, o conteúdo é retomado com tratamento diferenciado, e cada uma delas serve de patamar para o momento seguinte. As situações de ensino não são estanques e isoladas, ao contrário, são interligadas e interdependentes e, portanto, o limite entre elas não é claramente demarcado. Didaticamente, a M.M.D. é composta por momentos pedagógicos (etapas) denominadas de Resgatando/Registrando; Problematizando; Sistematizando e Produzindo (ARNONI, 2003).

\section{$1^{\circ}$ momento - Resgatando/Registrando:.}

Resgatar é buscar um mesmo ponto de partida para o processo de ensino, comum ao professor e ao aluno, por intermédio de diferentes linguagens: oralidade, desenho, recorte, dramatização, mímica, poesia, música, colagem, relato, texto escrito etc. $\mathrm{O}$ professor apresenta aos alunos uma série de atividades que envolvem o conteúdo trabalhado, e o aluno, ao desenvolvê-las, apresenta suas idéias iniciais sobre o referido conteúdo. Essa produção, ainda que de forma confusa, representa a objetivação do saber subjetivo do aluno. De posse dessas informações, o professor delimita o saber que o aluno possui do objeto em estudo e, comparando-o com o saber pretendido, depreende a tensão entre ambos e elabora a problematização. 


\section{$2^{\circ}$ momento - Problematizando:}

Problematizar é colocar o sujeito em uma situação de ensino problematizadora, capaz de levá-lo a compreender mentalmente as divergências entre seu saber imediato e o saber mediato trabalhado pelo processo de ensino. A problematização explicita as divergências entre esses saberes, tensionando-os pela contradição, e estimula o aluno a pensar e elaborar soluções por intermédio de seus saberes disponíveis e, simultaneamente, leva-o a perceber que seus saberes iniciais não são suficientes para a resposta suscitada. Essa contradição, além de gerar necessidade cognitiva (motivação), cria possibilidades para o sujeito investigar e buscar novas relações.

A atividade problematizadora, para ser percebida e compreendida pelo pensamento, precisa apresentar a qualidade particular de não facilitar e nem dificultar, em demasia, seu entendimento. Ela é capaz de gerar tensão entre o saber específico do aluno (imediato) e o saber geral da produção científica (mediato) e de estimular o aluno na busca de novos saberes.

\section{$3^{\circ}$ momento - Sistematizando:}

Sistematizar é desenvolver situação de ensino que ensejam ao aluno compreender as relações de sentido entre aspectos do seu saber imediato e elementos do saber mediato pretendido, por intermédio do diálogo. Esse diálogo, promovido pelo professor, favorece a explicitação dos aspectos da problematização, a discussão do saber científico a eles relacionado, potencializa que o pensamento gere a superação do imediato no mediato, a elaboração de sínteses cognitivas e a internalização do saber aprendido.

\section{$4^{0}$ momento - Produzindo:}

Produzir é desenvolver situações de ensino para que o aluno possa expressar as sínteses cognitivas elaboradas, ao vivenciar as etapas da "Metodologia da mediação dialética". O aluno, por intermédio das diferentes linguagens, representa o saber elaborado, os conceitos. É o ponto de chegada do processo de ensino, um saber provisório que se torna imediatamente um novo ponto de partida, constituindo-se em um elemento imprescindível para avaliar o referido processo.

\subsection{Prática Educativa}

Para representar a práxis desenvolvida no campo da educação, utiliza-se à expressão práxis educacional e, para a ação docente do professor, uma práxis educacional particular, recorre-se á expressão prática educativa: a aula na concepção filosófica. A práxis educacional (totalidade dinâmica) expressa-se nas práticas educativas (práxis particulares) e estas naquela.

A partir da conceituação da categoria práxis, pode-se compreender a práxis educacional e, em particular, a "Prática Educativa", que envolve o processo de ensino (professor) e o de aprendizagem (aluno). Nela, estes distintos processos estabelecem relações 
de tensão entre si, preservando suas identidades e potencializando aos alunos a elaboração de sínteses cognitivas, relativas ao conteúdo desenvolvido.

A característica essencial da prática educativa é a intencionalidade do trabalho pedagógico desenvolvido pelo professor (processo de ensino) objetivando influenciar o processo de aprendizagem (a relação do aluno com o saber). Nessa concepção, a prática educativa constitui um processo consciente, deliberado e sistemático, pelo qual se trabalha o saber cultural produzido historicamente por intermédio da relação pedagógica. A intencionalidade da prática educativa consiste em ensinar os bens culturais produzidos pelo gênero humano, para que o aluno, sujeito da aprendizagem, tenha uma concepção de ambiente menos imediata e, portanto, mais articulada, podendo, assim, agir criticamente e não de forma alienada.

Por essas razões, é relevante salientar que, nesta pesquisa, a palavra "prática" preserva o significado de práxis, termo filosófico, que não envolve forçosamente as conexões semânticas usuais de prática, como a-teórica.

O embasamento teórico, de cunho filosófico - a ontologia do ser social - permite compreender o professor no contexto da práxis educacional: um ser social e histórico, que se encontra imbricado em uma rede de relações sociais e enraizado em um determinado terreno histórico que sintetiza as relações de tensão entre diversos fatores que o compõem, de ordem social, econômica, política etc. Assim, a cotidianidade escolar de professor está condicionada, histórica e socialmente, pelo contexto ambiental (natural e social), e isso influencia sobremaneira a visão que ele tem da própria atividade, a prática educativa, e o leva a adotar, inconscientemente, os pontos de vista parciais, surgidos originariamente sobre o fato prático.

\section{AULA NA DIMENSÃO FILOSÓFICA DA PRÁXIS: PRÁTICA EDUCATIVA}

A aula não se resume, exclusivamente, no trabalho em sala de aula, este, constitui-se, apenas, em um dos seus momentos. A aula é uma totalidade dinâmica, um processo em desenvolvimento. Para compreender este movimento processual, é necessário entender a aula como práxis, um conceito filosófico que representa a ação do ser social, na qual se expressam os diferentes graus de consciência que o sujeito tem da relação teoria $\&$ prática.

Nessa perspectiva, a aula ou a "Prática Educativa", uma práxis educacional, caracteriza-se pela intencionalidade do professor que a desenvolve, a qual, sendo decidida $a$ priori, dirige o planejamento, o desenvolvimento e a avaliação da "Prática educativa". A intencionalidade de uma práxis educacional é a de articular, de forma consciente, teoria e prática, gerando uma práxis crítica, capaz desenvolver um processo de ensino que influencie no processo de aprendizagem e potencialize a compreensão do conteúdo pelo aluno. E para isso, esta intencionalidade da aula precisa ser compartilhada pelos sujeitos que dela participam, em especial, professor e aluno. 
A aula apresenta três etapas distintas e relacionadas: planejamento, desenvolvimento e avaliação. Estas etapas geram os pólos contraditórios da práxis educacional: o pólo teórico (planejamento e avaliação) e o pólo prático (desenvolvimento), daí considerar a aula como "Prática Educativa", cuja intencionalidade centra-se na articulação consciente da teoria com a prática.

O pólo teórico compõe-se de fundamentos teóricos de três naturezas: da área de atuação do professor, da área filosófica e da área filosófico-metodológica, as duas últimas sustentam o pedagógico. As teorias que embasam o pedagógico envolvem os fundamentos filosóficos da Mediação dialética e da "Metodologia da Mediação dialética".

\section{CONSIDERAÇÕES FINAIS}

Os fundamentos filosóficos da ontologia do ser social, (a) promovem o entendimento da práxis como expressão dos diferentes graus de consciência do ser social sobre a relação teoria e prática; (b) permitem a depreensão do caminho teórico, o método dialético, a partir desta teoria de compreensão do mundo e (c) exigem pesquisas teóricas que potencializem sua operacionalização em um processo de ensino.

Este texto apresenta, em especial, a "Metodologia da Mediação Dialética" que representa o influxo dos pressupostos teóricos da mediação na elaboração da práxis crítica, a "Prática de Ensino": aula na concepção filosófica. É uma proposição inovadora por explicitar a possibilidade de se estabelecer relação entre teoria e prática na organização e no desenvolvimento do conteúdo de ensino, em duas dimensões, na ação intencional do professor, ao planejar, desenvolver e avaliar a Prática Educativa, e, na ação do aluno, ao superar as representações do imediato no mediato, por intermédio da aprendizagem por compreensão. Outro aspecto inovador da pesquisa centra-se no fato de a M.M.D. fundamentar os processos de ensino e o de aprendizagem em um mesmo pressuposto filosófico, para os diferentes níveis de ensino, o básico e o superior. Ensino e aprendizagem, processos distintos e possíveis de se articularem na Prática Educativa, por intermédio de do conteúdo de ensino.

\section{Referências bibliográficas}

ALMEIDA, J. L. V. de (2001) Tá na rua: representações dos educadores de rua. São Paulo: Xamã.

ARNONI, M.E.B. (2003) Trabalho educativo e mediação dialética: fundamento teóricofilosófico e sua implicação metodológica para a prática. São Paulo: CD-ROM, Seminário Internacional de Educação - Teorias e políticas, ISBN:85-89852-03-2.

KOSIK , K. (1978) Dialética do Concreto. Rio de Janeiro: Civilização Brasileira.

LEFEBVRE, H. (1979). Sociologia de Marx. Rio de Janeiro: Forense Universitária. 